\title{
Article
}

\section{The Visual Matrix method in a study of death and dying: Methodological reflections}

Ramvi, Ellen, Manley, Julian Y, Froggett, Lynn, Liveng, Anne, Lading, Aase, Hollway, Wendy and Haga Gripsrud, Birgitta

Available at http://clok.uclan.ac.uk/21674/

Ramvi, Ellen, Manley, Julian Y ORCID: 0000-0003-2548-8033, Froggett, Lynn ORCID: 0000-0001-8406-6231, Liveng, Anne, Lading, Aase, Hollway, Wendy and Haga Gripsrud, Birgitta (2019) The Visual Matrix method in a study of death and dying: Methodological reflections. Psychoanalysis, Culture and Society, 24 (1). pp. 31-52. ISSN 1088-0763

It is advisable to refer to the publisher's version if you intend to cite from the work. http://dx.doi.org/10.1057/s41282-018-0095-y

For more information about UCLan's research in this area go to http://www.uclan.ac.uk/researchgroups/ and search for < name of research Group>.

For information about Research generally at UCLan please go to http://www.uclan.ac.uk/research/

All outputs in CLoK are protected by Intellectual Property Rights law, including Copyright law. Copyright, IPR and Moral Rights for the works on this site are retained by the individual authors and/or other copyright owners. Terms and conditions for use of this material are defined in the policies page.

\section{CLoK}

Central Lancashire online Knowledge www.clok.uclan.ac.uk

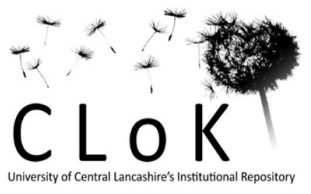




\section{Psychoanalysis, Culture \& Society \\ The Visual Matrix method in a study of death and dying: Methodological reflections --Manuscript Draft--}

\begin{tabular}{|c|c|c|}
\hline Manuscript Number: & \multicolumn{2}{|l|}{ PCAS-D-18-00009 } \\
\hline Full Title: & \multicolumn{2}{|c|}{ The Visual Matrix method in a study of death and dying: Methodological reflections } \\
\hline Article Type: & \multicolumn{2}{|l|}{ Original Article } \\
\hline Funding Information: & $\begin{array}{l}\text { The Joint Committee for Nordic research } \\
\text { councils in the Humanities and Social } \\
\text { Sciences } \\
(238169 / \text { F10) }\end{array}$ & Dr. Ellen Ramvi \\
\hline Abstract: & \multicolumn{2}{|c|}{$\begin{array}{l}\text { The Visual Matrix method is designed to elicit imagistic and associative contributions } \\
\text { established collectively amongst participants in a group setting. In this article, a hard- } \\
\text { to-reach area of experience - death and dying - illustrates the production of shared } \\
\text { cultural images beyond individual experience. Our dual purpose was to assess the } \\
\text { suitability of the method for this challenging topic, and to understand the ways in which } \\
\text { death figured in the imagination of the participants. Three theorists, Wilfred Bion, Alfred } \\
\text { Lorenzer and Gilles Deleuze, enable us to theorise psychosocial processes of } \\
\text { symbolisation beyond cognition. }\end{array}$} \\
\hline Corresponding Author: & \multicolumn{2}{|l|}{$\begin{array}{l}\text { Ellen Ramvi } \\
\text { Universitetet i Stavanger } \\
\text { NORWAY }\end{array}$} \\
\hline \multicolumn{3}{|l|}{$\begin{array}{l}\text { Corresponding Author Secondary } \\
\text { Information: }\end{array}$} \\
\hline Corresponding Author's Institution: & \multicolumn{2}{|l|}{ Universitetet i Stavanger } \\
\hline \multicolumn{3}{|l|}{$\begin{array}{l}\text { Corresponding Author's Secondary } \\
\text { Institution: }\end{array}$} \\
\hline First Author: & \multicolumn{2}{|l|}{ Ellen Ramvi } \\
\hline \multicolumn{3}{|l|}{ First Author Secondary Information: } \\
\hline \multirow[t]{7}{*}{ Order of Authors: } & \multicolumn{2}{|l|}{ Ellen Ramvi } \\
\hline & \multicolumn{2}{|l|}{ Julian Manley } \\
\hline & \multicolumn{2}{|l|}{ Lynn Froggett } \\
\hline & \multicolumn{2}{|l|}{ Anne Liveng } \\
\hline & \multicolumn{2}{|l|}{ Aase Lading } \\
\hline & \multicolumn{2}{|l|}{ Wendy Hollway } \\
\hline & \multicolumn{2}{|l|}{ Birgitta Haga Gripsrud } \\
\hline \multicolumn{3}{|c|}{ Order of Authors Secondary Information: } \\
\hline Author Comments: & & \\
\hline
\end{tabular}


The Visual Matrix method in a study of death and dying: Methodological reflections

\section{Authors:}

First author, Corresponding author:

\section{Prof. Ellen Ramvi}

Professor, Faculty of Health Sciences,

Address: University of Stavanger, Rennebergstien 30, 4021 Stavanger, Norway.

Telephone: +4751831000

[email: ellen.ramvi@uis.no]

\section{Co-authors:}

\section{Dr. Julian Manley}

Research Associate, Psychosocial Research Unit, School of Social Work, Care \& Community. Address: University of Central Lancashire, Preston PR1 2HE, United Kingdom [email: JYManley@uclan.ac.uk]

\section{Prof. Lynn Froggett}

Professor of Psychosocial Welfare, Director Psychosocial Research Unit, Honorary Professor at University of Roskilde, Denmark and Visiting Professor at University of Stavanger, Norway. Address: University of Central Lancashire, Preston PR1 2HE, United Kingdom.

[email: LFroggett@uclan.ac.uk]

\section{Dr. Anne Liveng}

Associate Professor, Center for Health Promotions Research, Department of People and Technology, Address: Roskilde University. Universitetsvej 1, P.O. Box 260, 4000 Roskilde, Denmark. 
[email: aliveng@ruc.dk]

\section{Dr. Aase Lading}

External Lecturer, Department of People and Technology,

Address: Roskilde University. Universitetsvej 1, P.O. Box 260, 4000 Roskilde, Denmark.

[email: alading@ruc.dk]

Prof. Wendy Hollway

Emeritus Professor of Psychology, Faculty of Social Sciences,

Address: Open University. Walton Hall, Kents Hill, Milton Keynes MK7 6AA, United Kingdom.

[email: w.hollway@open.ac.uk]

\section{Dr. Birgitta Haga Gripsrud}

Post-doctoral Fellow, Department of Health Studies,

Address: University of Stavanger. Rennebergstien 30, 4021 Stavanger, Norway.

[email: birgitta.h.gripsrud@uis.no ] 


\title{
The Visual Matrix Method in a Study of Death and Dying:
} Methodological Reflections

\begin{abstract}
The Visual Matrix method is designed to elicit imagistic and associative contributions established collectively amongst participants in a group setting. In this article, a hard-to-reach area of experience - death and dying - illustrates the production of shared cultural images beyond individual experience. Our dual purpose was to assess the suitability of the method for this challenging topic, and to understand the ways in which death figured in the imagination of the participants. Three theorists, Wilfred Bion, Alfred Lorenzer and Gilles Deleuze, enable us to theorise psychosocial processes of symbolisation beyond cognition.
\end{abstract}




\section{The Visual Matrix Method in a Study of Death and Dying:}

\section{Methodological Reflections}

Key words: containment; death; psychosocial; methodology; reverie

\section{Introduction}

(Authors project), an interdisciplinary research project financed by The Joint Committee for Nordic research councils in the Humanities and Social Sciences, focused on three transitions: from working life to retirement, from mental ability to dementia, and from life to death. The project was developed by researchers, who were also study participants (described below), sharing an interest in psychosocial research drawing on psychoanalytically informed thinking and relational, group-oriented as well as cultural and societal theories (Hoggett, 2010; Hollway, 2013;Roseneil, 2006, 2009; Urwin et al., 2013, Woodward, 2015). The visual matrix method (Authors, 2015; Authors, 2015; Authors, 2016; Clarke, 2017; Authors, 2017; Authors, 2017) is a psychosocial method developed in order to inquire into shared, internal worlds through images and affect to complement narrative and discourse-based methods, while not losing sight of the situating effects of the material and social milieu (Clarke and Hoggett, 2009; Hollway and Jefferson, 2013; Hollway, 2015; Macleod and Thomson, 2009; Walkerdine, 2010, 2014). (Authors project) offered an opportunity to explore the method through three workshops, one of which was on death and dying and generated data presented in this article. Our dual purpose was firstly to assess the suitability of the method for this extremely challenging topic, and secondly to use it to understand the ways in which death and dying figured in the cultural imagination of the workshop participants. A "sister" paper that specifically addresses the thematic issues in "thinking about what is hard to bear" was 
published in 2017 (Authors, 2017).

The research question for this workshop, 'how do people imagine and associate to death and dying?', is both transcendental and strikingly pragmatic. As such, we felt it required a psychosocial approach that could understand both the culturally situated aspects of death and dying, and feelings associated to what is unknown and yet certain that may evade articulation and conscious thought. The 'unthought known' (Bollas, 1987) arises from the fact that the subject is potentially painful and disturbing, and the existential questions at stake may provoke avoidance, disavowal and denial. This perturbing awareness of death is set against a valorisation of positive active ageing in western societies where neoliberal discourses of productivity, autonomy and self-care have taken root. Notions of active ageing often have a voluntaristic tenor which ignore the more challenging aspects of frailty and dependency experienced as death approaches, and the difficult feelings associated with it (Kitwood and Bredin, 1992; Kitwood, 1997; Gilleard and Higgs, 2011; Rozanova, 2012; Katz, 2000).

This study used the visual matrix method to explore the paradoxes that present themselves as we confront the subject of death: we are faced with a universal, inescapable prosaic "fact of life" (Money Kyrle, 1961) which is however set against a hinterland of mythology and religious belief. It might be argued that in the western world, secularisation has depleted the capacity of religion to provide meaningful narratives of death and dying; however, positive attitudes to death can still be sustained through religiosity and a non-denominational or 'cultural' spirituality (Lavik and Braut, 2016). In the visual matrix in our study, there were numerous allusions to religious or quasi-religious imagery which were primarily cultural in nature. These helped participants find a language for something that often evades representation, provokes anxiety and can only be accommodated through an effort of the imagination. As one of our participants remarked, 'I can't imagine myself dying or as a dead 
person'. The visual images and associations that emerged in the course of our visual matrix afforded participants ways of depicting their complex affective apperceptions of death and dying in a figurative language that was unavailable to them at the beginning of the process.

The theoretical perspectives that have informed the development of the visual matrix have helped to shape it as an instrument for accessing affective and embodied aspects of lived experience - in this case the fantasies and anxieties associated with death and dying. One such perspective involves the post-Kleinian psychoanalytical theory of thinking of Wilfred Bion (1962a, 1962b) that goes beyond conscious cognition to illuminate an emergent knowing based on emotional experience (Footnote 1) that he labels "reverie"; another, the conceptualisation of the "scene" and "scenic understanding" that is central to the work of cultural analyst Alfred Lorenzer (1981, 1986); and last, Gilles Deleuze's affect theory (2004), which identifies the shared affect that activates aesthetic sensibilities and constellations of images and ideas. Deleuze's concept of the affective rhizome and Lorenzer's notion of the scenic combine in the visual matrix to produce the concept of the 'scenic rhizome' (Authors, 2015), that is to say the combination of the interconnected interactions and relationships within the scenes configured in the matrix and between participants and these scenes. The rhizomatic nature of these interconnectivities develops through flows and intensities of affect linked to the imagery and ideas that the matrix produces. In our study, we demonstrate how complexities and paradoxes inherent in our subject matter are illuminated through this concept.

The conclusion reflects on our claims, namely that the visual matrix method succeeds in making accessible aspects of death and dying that are not often spoken about; that the psychoanalytically informed principles underlying the method enable shared thinking about this easily disavowed subject matter; and that the findings represent, not just the experiences 
and knowledge of a small group of individuals, but a wider cultural knowing about death and dying.

\section{Method}

In the following, we combine two aspects: on the one hand, we describe in general terms the principles of the method, and on the other, we also describe the specific procedure of our data collection for this present study.

\section{Participants}

The visual matrix on the transition from life to death was conducted in Norway with a group of nine academics, three from Denmark, three from Norway, one from Germany and two from the UK, three men and six women. The group represented different disciplinary backgrounds: cultural studies, nursing, pedagogy, psychology, social work, psychosocial studies, and theology. Ages ranged from 38 to 72 .

\section{Pre-matrix stimulus material}

Given that our interest in the visual matrix is to facilitate a form of affective expression that is image led rather than language based, the participants were first given an opportunity to begin 'thinking visually' around the subject matter of the research question. The participants were provided with paper and crayons to make drawings of their associations to the theme of transition from life to death. This exercise was intended to provide a context and stimulus for the work that ensues. Unlike previous uses of stimuli for the visual matrix (Authors, 2015; Authors, 2015), which used a slide show of images related to the subject matter of the research question, in this case it was felt that the deeply personal and sensitive nature of the feelings associated with death and dying were better expressed through this direct contact between the individual and her internal images, viscerally experienced and rendered visible. 


\section{The Visual Matrix Session}

The participants moved from the stimulus to the visual matrix itself. In a visual matrix, a process that typically lasts for one hour, participants do not talk to each other as they would in a group discussion or focus group, but rather offer their images and associations to a shared space. The lack of direct dialogue from person to person is encouraged by a "snowflake pattern" seating arrangement (see figure 1 below). In this configuration, images and feelings are offered to the listening group without direct eye contact. This seating arrangement, borrowed from the practice of social dreaming (Author, 2014), creates a sense of belonging to a collective body and communicative process while allowing for the production of a shared "collage" of images and associations.

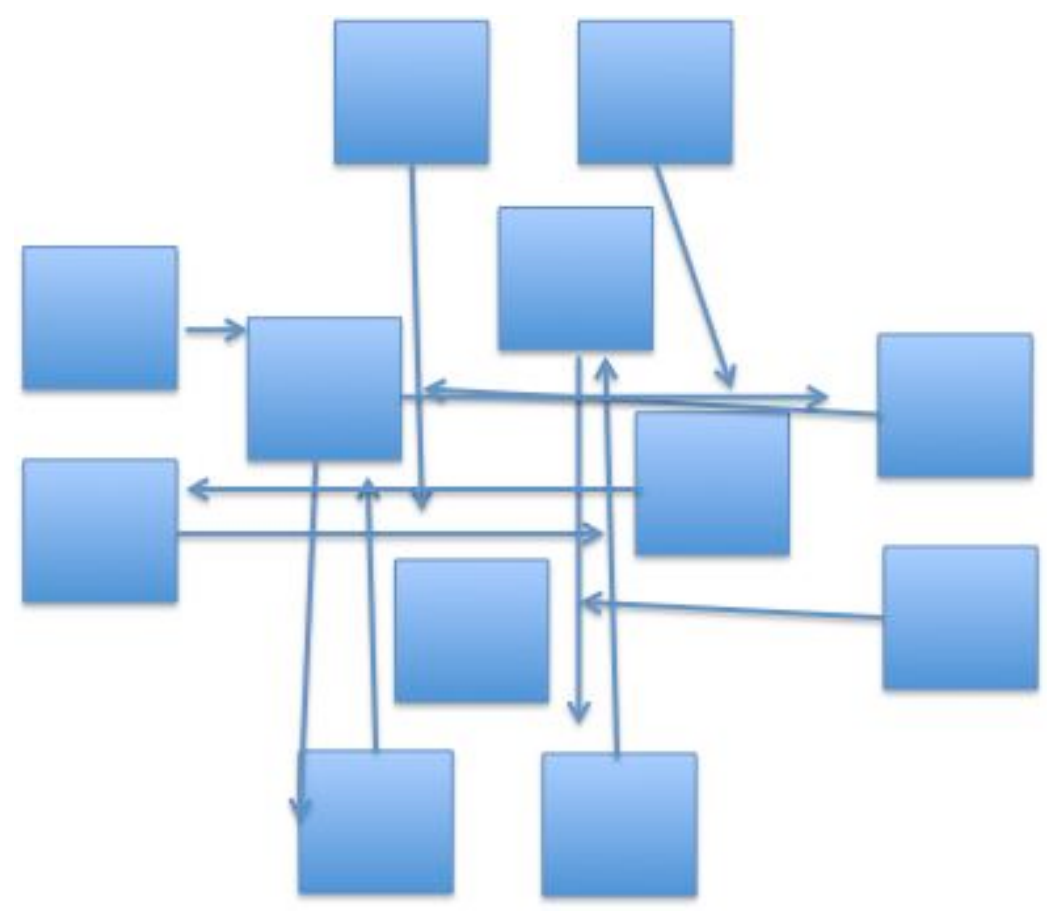

Figure 1: The snowflake seating arrangement in a visual matrix (arrows indicate the potential, indirect gaze of the participant) 
This configuration encourages participants to be receptive to free associations. At first, letting go of the safety of conventional everyday thinking and expression can be anxiety-provoking, but as the visual matrix session develops, the containing function of the matrix enables images and ideas charged with emotional experience to form within each participant, situated in the established space, until they are ready to be articulated. The matrix functions as a container that protects the participant from the anxiety of the raw, unprocessed feelings that emerge in this context; it then nurtures and transforms them into an emerging symbolisation.

The containment is fashioned by careful preparation: choice of room, seating arrangement, use of stimulus materials and introductory comments from the facilitator. Whenever there is a tendency to disallow or rationalise material, the facilitator will typically offer an association to model the process. This re-emphasises the free flowing, non-judgemental, non-interpretive nature of the thinking encouraged. The facilitator's own capacity for containment fosters the conditions under which the visual matrix itself becomes a container for thoughts to grow, take shape and find expression when the moment "feels right". This requires a tolerance of uncertainty, ambiguity and the anxiety that can easily threaten to disrupt the matrix. The session is audio-recorded and transcribed for analysis.

\section{Post-matrix Discussion and analysis process}

Following the visual matrix session, participants reconvene around a flipchart or similar and begin the process of interpreting the images, thoughts and feelings of the visual matrix, while the facilitator notes these on the flipchart and attempts to link them by way of an illustrative "mapping" - effectively a mind map of the matrix. This post-matrix discussion functions as the very first step of analysis, allowing the participants themselves to establish its frame. At the same time it offers them an opportunity to de-brief since the discussion focuses on the emotional experience of the matrix, as well as on the content. 
Both transcribed material and matrix mind maps are then analysed by the researchers. In the process of analysis the development and affective intensities of the presented images are identified, together with their substantive content and contextual resonance. The flow and content of the matrix cannot be separated as both inter-connected images and apparently new visualisations that arise during the matrix become integrated. The material resists being interpreted through thematically oriented methods of qualitative analysis (e.g. Braun and Clarke, 2006), which may reduce the complexity of the material by seeking to create clarity. By keeping in mind their positions as both participants and researchers, the research group combines perspectives on the matrix-material which have the apparent qualities of "inner" and "outer" experience. In fact these distinctions dissolve as the images produced afford psychosocial condensations built on personal and culturally situated lived experience. Understanding how these emerge, resonate, acquire intensity and link with other such imagistic condensations to form the scenic rhizome is central to the interpretation process. The rhizome metaphor aptly captures the way in which themes and associations run between and across images and concentrate in complex knots and affective intensities.

\section{Summary of the matrix data on transition from life to death}

The following summary provides an overall feel for the quality of the imagery that emerged from the matrix as a whole; the variety of associations that were elicited, their interconnectivity, their experience-nearness and their affective complexity.

The first images that emerged from the participants' drawings included familiar archetypal subjects, such as old trees, fire and water. Connected to images of water were references to the fear of being unable to rescue drowning children. A funeral theme followed, starting with a cemetery, continuing with images of graveyards and crematoriums. Then a more haunting image arose which combined death and water: driving from an island, through an underwater 
tunnel with a dead body in a car 'the smell, the car windows all open and down deep through an underwater tunnel and up again. This appeared to allude to archetypes of rebirth or baptism through water, while the fear and reality of death was encapsulated in the very physical smell of the body. The matrix continues with images of a dead child, followed by images of death with other sensory associations: the dead grandmother with 'sweat on her brow', a man just died who 'was still warm'. A theme of death of family members followed, being there or not when someone was dying, then a desperate recollection of a time when one of the participants 'felt that maybe it's better to die', followed by reports of blankness. From this blankness a change of theme introduced animals, initially with a lightness of tone but then leading to animal deaths and a merging of these images with human deaths. Further images of parents and grandparents generated questions and guilt related to another's death. The image of an empty bed after death was followed by an image of a child killed in a car crash - 'what was left to touch was the hand'.

\section{Psychosocial Analysis: Affect and Emergent Symbolisation}

The matrix uniquely enables Bion's (1962a) unprocessed 'Beta' elements, the "unthought”, to be brought into symbolisation in a social forum. It achieves this through privileging the expression of affect over cognition. It differs from other group-based methods such as the focus group by encouraging free associative visualisation, which generates - in Suzanne Langer's (1948) and Alfred Lorenzer's $(1981,1986)$ terms - “presentational symbols, as opposed to discursive symbolism or language proper" (Langer, 1948, p. 79). Because the visualisations the matrix are affectively laden and these have priority over the linearity of discursive language, the visual matrix becomes a rhizome - in the Deleuzian sense - of affective embodied experience. The matrix is led by visual imagery so that although words are used to voice the images, they have a figurative character and retain a sensory, sometimes 
poetic quality - in other words the language itself is infused by affect and the symbolisations produced are presentational in nature.

When presentational symbolism predominates, the matrix gives rise to complex embodied metaphorical constructions and associations - some of them very extended. We illustrate this through images of water in the matrix. Water contained and expressed multiple, condensed layers of meaning that creatively accessed inchoate experience. The water images also illustrate the way in which a visual matrix whole rooted in individual experiences also manifests in a shared, socio-cultural set of ideas with wider societal resonance.

\section{Water as metaphor, symbol and affect}

A few minutes into the session the first water image arises: '...swimming through time, at one time stepped upon an island for work, then jumped into the sea and swimming into retirement and finally swimming slowly towards death'. Here water is converted into an illustration of the 'journey of life' which provides a framing for the subsequent images of water in the matrix. The water images continue through nine subsequent contributions, with impressive diversity and continuity. 'Swimming through time' leads to the idea of a 'river that separates the person who is dying from the living'. However, in the next contribution, the river becomes an 'angry cascade', an indistinct swirling mass which threatens to break up the 'journey' by evoking an inability to hold on to any clear image. This is then opposed by a watery image of birth - amniotic fluid.

The life course becomes a source of anxiety in four images of children in water where parents did not protect them from drowning: the deep end of a pool; an air bed drifting out to sea; failing to catch a child at the bottom of a water slide; and (combining a report of an emotional state with an image of a sinking ship) being frightened to take children on a ferry after a high 
profile disaster. The extremity of affect produced by failure of parental protection is offset by mourning at the passing of mothers and grandmothers: a comment about a hospital allowing a mother '[to die] of thirst' and a peaceful image of a recently departed grandmother with 'sweat on her brow'. In the context of the visual matrix, these references to water in old age and death link up to those related to birth, implying the cycle of life that is both fearful and hopeful and so difficult to comprehend and express. This complex interweaving of accumulated images and affect is typical of visual matrix data. The images of death in old age can be associated with each other, with birth, with the generations and with fear of death before the proper time.

Images in a visual matrix are offered or taken up in succession or rhizomatically, triggering further associated images. During the analysis, it became apparent that images of water expressed the different ways people cling to life, the existential difficulty of facing death, remembering the loss of loved others, and fearing death, especially of a younger generation. Death was frequently imagined as a shocking and unwanted interruption of normality, joy, and being. When water images were related to danger, the implication was a horrifying loss of control - that life and death could literally be out of our hands, as in the associations to slippery babies and slippery slopes in swimming pools and to a boy drifting out to sea on an air mattress. The water imagery washes over boundaries, blurring the initial line drawn between the dying and living ('there's a line between them and me because I don't want to $\left.d i e^{\prime}\right)$. Water is ambiguous: archaic and originary in its links to nature and evolution, yet also a threatening and deadly force - as such it may evoke both safety and danger. The amniotic fluid also contained this duality, representing the enigmatic quality of water, which can contain and separate: the thin membrane of the amniotic sack demarcating a semi-transparent boundary between foetus and the mother, destined to rupture during birth. 


\section{The provision of containment when eliciting the hard-to-think}

The visual matrix method aims to elicit the daydream-like state or "waking dream" that Bion (1962a) calls reverie, which in his theory of thinking enables the processing of emotional experience or affect. In its original form reverie is an intersubjective state, originating in the container/contained relationship of the mother-infant pair. The baby's experiences are lodged, without conscious awareness, in the mother who, if she is able to process them through reverie, can return otherwise chaotic and anxiety-provoking sensory bombardment in a bearable form. This creates the foundation for later thinking in adult life. The connection between hard-to-think experience, reverie and containment is important in our use of Bion's conceptual framework: it accounts for the centrality of containment as a principle feature of the matrix achieved through a combination of procedure and facilitation. Participants can allow the "unbidden" to emerge (Oeser, 2010, p. 9), in this case the hard-to-think experiences of death and dying, which necessarily go beyond personal experience, embedded as they are in cultural practices and the universal inevitability of death. These are conjured imaginatively in the containment of the matrix, which proceeds through participants building on each other's contributions.

For example, in the following contributions about hating crematoriums and two images of rural graveyards, the image of a family graveyard affords containment that "travels" (Thomson et al., 2012) beyond the contributor:

'... the graveyard where my family comes from and I have a cottage, and a close relationship to the place, and it's a beautiful graveyard and it's like I feel safe to be buried there. And I, I can't feel I want to be burned [cremated], I want to lay under the ground beside and have family around.'

After facing ineffable existential questions concerning death and dying through the images of 
crematoriums in the matrix, this image of a burial practice, established over many generations, continued to provide containment.

The underlying epistemology of Bion's theory of thinking (1962b; Ogden, 2009) contrasts with the cognitive-rational model and foregrounds the relationship between emotional experience, thinking and intersubjective containment that informs the design of the visual matrix. Some aspects of death will be outside our capacity to think altogether. Others will be thought or spoken of in terms that tame their painful aspects. Based on Bion's epistemology, the visual matrix becomes a container of participants' emotional experience and supports reverie, thus enabling the participants to go beyond consciously aware and discursive thought. This was one of the reasons behind previous use of the snowflake pattern in social dreaming, and the reason for our use of it in the visual matrix. In this way, participants avoid face-toface contact and are encouraged to let go of the ego, the 'in control' part of the self. This facilitates associative thinking. Through the reverie of the matrix, participants are encouraged to process embodied experience into thought.

\section{The relation between symbolisation and the socio-cultural domain}

While Bion's theory of thinking and the concept of containment transcend the binaries between emotion and cognition and between intra- and inter-subjective dynamics, it does not theorise the relation of symbolisation to the socio-cultural domain, essential to a psychosocial perspective. As we illustrated with the empty hospital bed and graveyard examples above, the visual matrix data show that associations resolve into holistic expressions of socio-cultural significance. Below, we develop this claim using Lorenzer's concept of scene.

In the work of Lorenzer, "imagination is scenic in its format: it interrelates all informative, sensual and situated impressions in holistic images" (Salling Olesen, 2012, para. 3). His 
concepts of "the scene" and "scenic understanding" emphasise the cultural aspect of aesthetic experience. Lorenzer was primarily concerned with the interpretation of literary texts, which are replete with imagery and the very idea of the scene evokes a visual register. Lorenzer regards the scene as "an affective and embodied register of meaning" (Bereswill et al., 2010, p.225), composed of sensual symbolic interaction forms (the basis of presentational symbolisation) felt in the body and shaped by socialisation and cultural practices. The work of scenic understanding transforms these into the symbolic interaction forms of language which can either retain its vitality through a living link to sensuous experience or become abstracted from it in the clichés of conventional discourse. It the visual matrix we witness a process whereby the sensual symbolic achieves linguistic form and this is why the verbal expressions of the matrix retain a freshness and often a poetic originality bound to its imagery and other sense impressions.

In this study the cultivation of visual images, first through drawing and then in the matrix, produces scenic experience: the cottage and rural family graveyard would be available to participants through paintings or novels, if not in personal memory. The shared cultural familiarity of the scene (at least within Christian cultures) evokes a resonating familiarity among participants. Culture affords "a social level of reality which is present both as an environment and as an embodied meaning of the individual"' (Salling Olesen, 2012, para. 10). A binary common in western thinking is thus breached in Lorenzer's refusal of radical demarcation between the individual and socio-cultural (Froggett and Hollway, 2010; Redman et al., 2010), and this is central tenet of a psychosocial approach. Furthermore - like Bion Lorenzer's thory of symbolisation defies binaries of cognition-emotion and body-mind (Hollway, 2015, p.74) 
For example, one participant remembered the process of her grandmother's dying, starting

before the ambulance arrived at hospital while the daughter and granddaughter followed in a car behind:

'We saw her body in the hospital, it had been laid in a bed and it was very peaceful, and obviously she had only just died so there was sweat on her brow, and I remember touching her brow, and you know she had perspiration, and was so warm. It was a strange and beautiful moment in my life'.

The image is powerfully scenic: it is an individual's narrative, replete with sensuous memory and personal emotion, and at the same time a ritual of shared cultural significance. The sensation of damp, warm perspiration is directly communicated by touching, both affective and tactile. The sweat seems to be a liminal condensation of the warmth of life as well as of a struggle that is now over, leaving its protagonist at peace. Later, this prompted an opposite association: '[my mother] by the time I got there, she had gone completely cold and I had never ever felt anything like cold flesh, cold dead flesh.' In the bringing together of opposites in this way a whole scene, composed of two images together, is linked by the image of water in the form of sweat.

The image of touching the dying came after a train of associations about holding pets while they were 'put down' and permitting the death of 'a suffering tiny, tiny, tiny bird,' mauled by a cat: 'I was holding, holding the life and then ending the life with my hands. You know the feeling of a little heart beating and then the gruesomeness of having actually pulled it in two'. The affect transmitted in the relationship to the dying through animals resonates with bodily aversion to human death ' ... just to hold a dead animal. It's, it's like I am shivering, my whole body'. When she clears away a dead bird she has 'to take paper and plastic and everything just to hold on it ... just the feeling of holding something dead, it's like so terrible'. 
Although this aversion is individually felt, we are aware that in these images, it is in part produced by an avoidant culture, ill at ease with death and its physicality. This avoidance is partially processed through the cradling and disposal of an animal and then resolved in the scenic understanding produced by the human death scenes that follow.

\section{Condensation, scenic images and affective intensities}

Lorenzer's concept of the scenic, with its strong visual register and its holistic character, draws on Freud's original understanding of condensation. It links to the multiply layered and scenic character of dreaming, drawn on in the visual matrix method through its emphasis on reverie and in its origins in social dreaming. The scenic quality of images produced through a process of reverie in the matrix is, as in dreams, often due to "condensation". In Freud's theory of dream work (1900), condensation, refers to a process where the manifest dream image represents several latent thoughts or wishes which - due to the censorship of the superego - cannot find undisguised expression. Several unconscious and preconscious thoughts may then converge into one image; that is, it becomes culturally or biographically over-determined. In the context of the matrix, participants draw on both aspects, adding new meanings which by association come together and are condensed into one image. In this way, not only are the participants encouraged to speak about what to most of them is difficult, they also get ideas and construct images around a theme that they would not have produced on their own.

Image selection is an important aspect of visual matrix data analysis in that researchers have to consider the extent to which images with a specific scenic quality are governing or framing the development of the matrix. What images or clusters emerge most strongly in a complex matrix? What impact do these have on other images? The hypothesis suggested by our conceptual framework is that the images which are most scenic and most condensed have the 
quality of holding multiple relevant affect-laden meanings which are emerging into symbolisation.

In the meandering images in the matrix we saw several contributions which focussed on fears that one's child or children would die, worst of all through accidents caused by one's own carelessness. In three contributions there are, however, references to scenes where a child has actually died and a mother is grieving. According to Lorenzer (Bereswill et al., 2010), the emotional impact of such images is all the stronger as they conflict with culturally available memory traces ("engrams") of interaction forms, in this case that of lifegiving mother-andchild. One image presented in the matrix describes a mother driving home the body of her son who had committed suicide. Right after that, a participant comes up with a reference to Käthe Kollwitz' Pietà - "Mother with her Dead Son" - which is exhibited in a Berlin memorial dedicated to the victims of war. The participant said

'[the Pietà] is an image of the mother holding the dead son in her lap, and its, it has, the building it is in has a hole in the roof which means that the light can come in, but also the rain pours down on the mother. The grieving mother and her dead son. It's a very haunting piece and a haunting place. It's also very beautiful.'

Kollwitz' condensation of multidimensional and superimposed scenes in the sculpture turns an individual experience of loss into a socio-cultural aesthetic object, affording identification with the sadness of all mothers whose soldier boys died in war and, by extension, all mothers (and others) who have lost, or dread the idea of losing, children to death. In this way, the reference to Kollwitz' Pietà engenders at the same time an experience of something 'out there' and 'in here', something known and unknown, personal and social.

Following this intervention, there is a long interval before the theme of death of a child reappears at the very end of the matrix. It is presented in another haunting image of a child, 
killed in an accident where the parents were involved. Due to extensive injuries, the body had been covered by a sheet, with only the child's hand allowed to be visible - while 'the mother you know [is] going around trying to find some [part of the] body to hold on to'. This may be an associative link back to Kollwitz' sculpture with its layer of religious meaning through Pietà: perhaps Christian discourse offers something to hold on to. However, introduced in the secular setting of the matrix, a participant comments on the powerlessness of Christianity in the face of death and dying, including a generalized reference to the Kollwitz statue: ' $I$ am aware of being, um.., quite blank when trying to associate the images of graveyards and crosses and statues of mother and dying son, chapels, churches. Um, I actually have an image of blankness'. Here blankness appears to replace religious imagery but has no imagery to substitute. In Bion's framework, this could be understood as "not thinking", a lack at that moment of the kind of containment offered by cultural imagery (Britton, 1998, p.21), depriving the speaker of a form in which to bring raw emotional experience to symbolisation.

As the scenes resonate with each other and accumulate in a complexity, the matrix is transformed into a Deleuzian-like rhizome of intensities of affect, where original sequences of associations are disturbed and temporarily rearranged in different configurations. This is felt in how the image of Pietà combines with the other images containing water, leading to an understanding of meaning through affect before it can be deconstructed and cognitively understood. Through this interlacing of images, the affective meaning of the whole is lifted towards an awareness of a multiplicity of contrasting sensations that - by this very forcing together of paradox - are easier felt than than expressed in language. As we have seen, the images of water build up different aspects of scenic understanding, the matrix 'collages' these into a 'scenic rhizome' (Authors, 2015) and brings together Lorenzer's scenic sensibility with the Deleuzian concept of affect in the rhizome. It also suggests that Bion's Beta elements are 
not all successfully transformed by Alpha function in the process of the matrix and are felt as intense affect before they are necessarily understood.

For example, by the time we reach the halfway point in the matrix, we are presented with a complex representation of life and death in an image of a man's death on an island and the transportation of his body by the undertaker in his car, first by a ferry on the water, and subsequently through an underwater tunnel. By this time in the matrix, the journey by boat resonates "rhizomatically" with previous images of being adrift on a mattress at sea and ferry disasters (an association to the song "Don't pay the ferryman" condensed some of these.) That is to say, the unprocessed affective experiences of loss and guilt of the previous images 'echo' the scenic of the dead person's last voyage. In a Deleuzian sense, at this moment these three specific images of sea vessels - mattress, ferry and boat - light up and combine in affective intensity alongside their symbolic potentials. These in turn are further linked to other images of water, but in no particular order. In the rhizome meanings emerge not through order but through intensities of feeling linked by random, non-hierarchical inter-connections between things, rather than through rational, sequential thinking (Deleuze and Guattari 1988, pp.3-25).

A rhizome will have particular nodes of importance. In this matrix, the image of the Pietà is a case in point. What might have become a clichéd representation or symbol (that of the Mother and Child in its countless religious representations), in the matrix becomes both affectively intense and cognitively symbolic. This is because of the way the water image is emphasised. The point made about this particular Pietà is that 'the building it is in has a hole in the roof which means that the light can come in, but also the rain pours down on the mother'. In the context of the matrix, we consider the rain as a continuation of the water image, but by now the water has become powerfully felt as both life-giving (which we have seen before in the reference to amniotic fluid) and an expression of the deepest sadness and mourning at the 
coming of death. It is through the affectively-laden intrusion of water from the repetition of

the cultural symbolism of the Pietà that an intensity of affect is created. In this way, the repetition of the cultural symbol is evoked with an essential difference that makes the moment unique (Deleuze, 2004). It is this image of the mother and child in the matrix that makes the repetition of the archetypical symbol special and different from its role as a cultural symbol only; and it is through the interconnectivities of the rhizome that these paradoxes can be joined: the rain coming through the roof onto the Pietà is combined with light; sadness with joy, in impossible union. The way Deleuze would describe this impossible experience of affect within the rhizome is "becoming" (Deleuze and Guattari 1988, p.239): there is a possibility of becoming the juxtaposed complex combinations of affect as represented in the intensities of the rhizome, and through this experienced knowledge being more able to reach towards some unspoken understanding of the meaning of the transition from life to death.

\section{Ethics}

Reflecting upon the use of the visual matrix with such a difficult topic has made us consider the ethical implications of agitating unsettling emotions through Deleuzian affective becomings, where Bion's process of transformation from raw data to thinking is only ever partly achieved and where the Lorenzerian scene becomes so many scenes within scenes that complete resolution is impossible. Deleuze sees only creativity in affective becomings. Bion places the "digestion" of emotional experience as central to the symbolisation that underpins the capacity for new thinking and also equates this "learning from experience" with a similar sense of becoming, contributing insights into the role of intersubjective and cultural containment. Lorenzer enables us to recognise the central role of cultural meanings in symbolisation, which is also affective and embodied. In all three frameworks, unsettling is a requirement in understanding change and transition. 
It is common for research ethics advice to recommend avoidance of upsetting topics. We counter this emphasis on avoidance by reference to the principle that to be unsettled can be helpful when difficult topics can be approached in the contained setting of the matrix with an experienced facilitator.

Nevertheless, ethical challenges remain: how can we understand and formulate the meaning of the sum of participants' multifaceted contributions (Nagbøl, 2003)? After the post-matrix session in which participants collectively reflect on their experiences in the matrix, the research group takes ownership of the material. Typically in qualitative data analysis, a central ethical question is whether participants can expect that what they say is understood in a way that accords with their intentions. Our answer changes the focus: it is not any individual who is "interpreted". This principle is inscribed in the very design of the visual matrix and is respected throughout data analysis. Our analytic objects are scenes in a rhizomatic flow that can take on specific socio-cultural meanings. One implication may be that a degree of cultural homogeneity amongst participants is a strength, to the extent that shared cultural referents, as we have seen, can be more easily extrapolated from the data, respecting boundaries as to their scope and limits.

The ethics of interpretation is much debated among psychosocial researchers (Frosh and Emerson, 2005; Hoggett et al., 2010; Stopford, 2004; Wetherell, 2008) and our psychosocial focus nonetheless requires that we address the question of how we formulate meaning from this kind of data. When we "translate" complex affective visual images into thoughts, some aspects are lost and some preserved. Given our conceptual emphasis on the role of affect in meaning making, it is crucial to preserve the vitality of meaning in this process. An important part of the facilitator's job is to help the matrix (and afterwards the reflection group) to preserve the affective substrate of the language. This requires abstaining from premature 
closure by tidying up into a coherent narrative, interpretation and categorisation, intellectualisation of affect and any idea, claim or statement that closes down rather than further opens up. The strength of the method lies in focusing not on individual participants but on their shared cultural forms and expressions of affect, and this has ethical as well as ontological significance.

Moreover, the principle of researcher reflexivity (Hollway, 2016) and our recognition of the unsettling character of the topic leads us to inquire within our own experience as participants. This particular matrix was often unsettling but not distressing. We tended to leave sessions feeling lightened, wanting more; we found ourselves dreaming and daydreaming echoes of the images emerging in the matrix. Transformations that the research experience wrought in our own relationships to death and dying were enhanced by the richness of the images that the matrix provided; the images' multiple layers of condensed meaning felt like a bounty. This can be explained by the fact that we experienced the inevitably hard-to-bear aspects of death and dying in a containing setting, as an experience which could therefore be shared and brought into thought.

\section{Was Something Differently Achieved?}

Since death and dying as a research topic is hard to bear and difficult to represent, the research team had to reconsider most aspects of the research: design, setting, epistemology, ethics and data analysis. We had to ask: How do we speak of something that evades representation? In this final section, we summarise a response to this question and assess the quality of the data produced; the appropriateness of our conceptual resources and the psychosocial nature of our analysis and conclusions. 
We claim that through a detailed account of the method and data analysis, our approach made

accessible the elusive aspects of death and dying, notably the emotional experiences and existential fears that surround the topic, which are hard for many - including the dying and their carers (Ramvi and Gripsrud, 2017) - to express. Psychoanalysis offers us the idea that anxiety-provoking ideas and experiences are liable to avoidance, disavowal and projection; it also suggests practical means of bringing such threatening ideas to symbolisation: reverie, visualization, free association, and containment. Psychosocial approaches have taken such ideas further by going beyond individual mental processes to demonstrate their inextricability with socio-cultural sources of meaning and intersubjective affect.

Psychosocial theorization of a shared unconscious, including the symbolisation processes that emerged from the setting of the visual matrix became our key interest, both methodologically (how to produce and register them for research purposes) and substantively (how to analyse the data generated in the visual matrix, in order to produce knowledge of a depth and complexity that does justice to experiences of death and dying). The first test of our success is in the quality of the data generated in the visual matrix session on which this article is based. We have attempted to provide breadth (a summary of emerging themes) and depth (detailed treatment of the water images). We have demonstrated the multiple character of single images and the chains and collages of associations that build up over the course of participants' contributions, aided by the concepts of condensation, scenic understanding and rhizomatic intensities. These sensitized us to the cultural complexity and affective intensity of the images generated - images and meanings that are usually unavailable for thinking. So, the second test of our success has to be the appropriateness and power of the conceptual tools we used to comprehend and illuminate in depth the data generated by the methodology. To demonstrate this, we worked by moving between data and conceptual analysis, staying close to specific examples so that their affective resonances remain available to readers. The third test is 
whether our analysis succeeded in being psychosocial, that is moving beyond individual contributions to demonstrate a culturally situated, shared and affectively embodied analysis of contemporary experience of death and dying and how this is simultaneously reproduced, transformed and assimilated through the embodied self and shared cultural meanings. Our theorizing of processes of symbolisation - a synthesis of the three theoretical frameworks described - was key to enabling this.

\section{Acknowledgments}

The workshop series (Authors project) (2014-15) was funded by the Joint Committee for Nordic Research Councils in the Humanities and Social Sciences (NOS-HS). We thank the invited participants for their contributions to the research.

\section{Conflict of interest}

On behalf of all authors, the corresponding author states that there is no conflict of interest.

\section{Footnotes}

1. We use the concepts of feeling, emotional experience and affect in different contexts and sometimes interchangeably. The word "feelings" is used non-technically to cover the whole field denoted by emotions and affect. The word "emotion" rarely figures because in some contemporary usage it refer to conscious experience, already verbalised (Blackman and Cromby, 2007), whereas our central purpose here - the territory opened up by the visual matrix method - is to explore areas of emotional experience that are hard to reach through available discourses. Whereas the idea of emotional experience is central to Bion's theory, and unconscious emotions figure strongly in the work of Lorenzer, Deleuze uses "affect", but all three share an emphasis on embodied, dynamic processes linked to symbolisation, and this is of 
critical importance in understanding the visual matrix. As these ideas are developed in the course of this article, the term "affective" most often covers the necessary ground. The considerable theoretical debate on these terms (for example, Day Sclater et al., 2009; Greco and Stenner, 2008; Redman, 2009) is not a priority for our purposes here.

\section{References}

Bereswill, M., Morgenroth, C. and Redman, P. (2010) Alfred Lorenzer and the Depthhermeneutic Method. Special Issue on Alfred Lorenzer. Psychoanalysis, Culture and Society 15(3): 221-250.

Bion, W. (1962a) Learning from Experience. London: Karnac.

Bion, W. (1962b) A theory of thinking. International Journal of Psycho-Analysis 43: 306310 .

Blackman, L. and Cromby, J. (2007) Editorial: Affect and Feeling, Critical Psychology 21: 522.

Bollas, C. (1987) The Shadow of the Object. London: Free Association Books.

Braun, V. and Clarke, V. (2006) Using thematic analysis in psychology. Qualitative Research in Psychology 3: 77-101.

Britton, R. (1998) Belief and Imagination. Explorations in Psychoanalysis. London: Routledge.

Clarke, C. (2017) Re-imagining Dementia using the Visual Matrix. In "Seeing with the Mind's Eye: social work and the visual imagination", Journal of Social Work Practice (Special Edition) 31(2): 173-188

Clarke, S. and Hoggett, P. (2009) Researching Beneath the Surface. London: Karnac.

Day Sclater, S., Jones, D.,Price, H. and Yates, C. (eds.) (2009) Emotion: New Psychosocial Perspectives. London: Palgrave.

Deleuze, G. (2004) Difference and Repetition. London: Continuum.

Deleuze, G. and Guattarri, F. (1988) A Thousand Plateaus. London: Continuum.

Freud, S. (1900/1955) The Interpretation of Dreams. Standard Edition 4/5 London: Hogarth Press. 
Authors (2015)

Froggett, L. and Hollway, W. (2010) Psychosocial research analysis and scenic understanding. Psychoanalysis, Culture and Society 15(3): 281-301.

Frosh, Stephen \& Emerson, Peter (2005). Interpretation and over-interpretation: Disputing the meaning of texts. Qualitative Research, 5(3): 307-324.

Gilleard, C. and Higgs, P. (2011) Ageing abjection and embodiment in the fourth age. Journal of Ageing Studies 25(2): 135-142.

Greco, M. and Stenner, P. (2008) Emotions: A Reader. London: Routledge.

Hoggett, P., Beedell, P., Jimenez, L., Mayo, M. and Miller, C. (2010) Working psychosocially and dialogically in research. Psychoanalysis, Culture and Society, 15(2): 173-88.

Hoggett, P. (2010) Perverse social structures. Journal of Psycho-Social Studies 4(1) http://www1.uwe.ac.uk/hls/research/jpss/volume412010.aspx

Hollway, W. (2013) Locating unconscious "societal-collective" processes in psychosocial research. Organisational and Social Dynamics 13(1): 22-40.

Hollway, W. (2015) Knowing Mothers: Researching Maternal Identity Change. London, Palgrave.

Hollway, W. (2016) Emotional experience plus reflection: countertransference and reflexivity in research. The Psychotherapist 62: 19-21.

Hollway, W. and Jefferson, T. (2013) Doing Qualitative Research Differently: Free Association, Narrative and the Interview Method. 2nd ed. London: Sage.

Katz, S. (2000) Busy bodies: Activity, Ageing, and the Management of Everyday Life. Journal of Ageing Studies 14(2): 135-152.

Kitwood, T. (1997) The Experience of Dementia. Aging and Mental Health 1(1): 13-22.

Kitwood, T. and Bredin, K. (1992) Towards a Theory of Dementia Care: Personhood and Well-being. Aging and Society 12(3): 269-287.

Langer, S.K. (1948) Philosophy in a New Key: A Study in the Symbolism of Reason, Rite, and Art. Boston: Harvard University Press.

Lavik, M.H. and Braut, G.S. (2016) Tru og bibelbruk som meistring ved alvorleg sjukdom [Eng. Faith and uses of the Bible in coping with serious illness], Omsorg: Nordisk tidsskrift for palliativ medisin 1: 15-19.

Authors 2017 
Lorenzer, A. (1981) What is an unconscious phantasy? Tr. T. Schaffrik. pp. 29- 41. http://bidok.uibk.ac.at/library/schaffrik-lorenzer-work-e.html, accessed March $3^{\text {rd }} 2017$.

Lorenzer, A. (1986) Tiefenhermeneutische Kulturanalyse. In A. Lorenzer (ed.) KulturAnalysen: Psychoanalytische Studien zur Kultur. Frankfurt/M: Fischer, pp.11-98

McLeod, J. and Thomson, R. (2009) Researching social change: qualitative approaches. London: Sage.

Author (2014)

Author (2015)

Author (2016)

Money-Kyrle, R. (1961) Man's Picture of His World: A Psycho-analytic Study. New York: International Universities Press.

Nagbøl, S. (2003) Sociologi og pædagogik som forskningsfelt og praksisorienteret menneskevidenskab [Sociology and pedagogy as a research field and practice- oriented human science]. In I. M. Bryderup (ed.), Pcedagogisk sociologi [Pedagogical sociology] Copenhagen, Denmark: Danmarks Pædagogiske Universitets Forlag, pp.119-145.

Oeser, F. (2010) Social Dreaming to creativity. In G. W. Lawrence (ed.) The Creativity of Social Dreaming. London: Karnac, pp. 9-24.

Ogden, T. (2009) Rediscovering Psychoanalysis: Thinking, dreaming, learning and forgetting. London: Routledge.

Ramvi, E. and Gripsrud, B.H. (2017) Silence about encounters with dying among healthcare professionals in a society that 'de-tabooises' death. International Practice Development Journal 7 (Suppl) [3] pp.1-12

Redman, P. (2009) Affect Revisited. Subjectivity 26(1): 51-68.

Redman, P., Bereswill, M. and Morgenroth, C. (2010) Introduction. Special Issue on Alfred Lorenzer. Psychoanalysis, Culture and Society 15(3): 213-220.

Roseneil, S. (2006) The ambivalences of Angel's "arrangement": A psychosocial lens on the contemporary condition of personal life, Sociological Review 54(4): 847-869.

Roseneil, S. (2009) Haunting in an age of individualization, subjectivity, relationality and the traces of the lives of others, European Societies 11(3): 411-430.

Author (2017) 
Rozanova, J. (2010) Discourse of successful aging in The Globe \& Mail: Insights from critical gerontology. Journal of Aging Studies 24(4): 213-222.

Salling Olesen, H. (2012) The societal nature of subjectivity: An interdisciplinary methodological challenge, Forum: Qualitative Social Research 13(3), Art.4.

http://www.qualitative-research.net/index.php/fqs/article/view/1908/3446

Stopford, A. (2004) Researching postcolonial subjectivities: the application of relational (post-classical) psychoanalysis to research methodology, Critical Psychology 10: 13-35.

Thomson, R., Moe, A., Thorne, B. and Nielsen, H.B. (2012) Situated affect in travelling data. Qualitative Inquiry 18(4): 310-322.

Urwin, C., Hauge, M.I., Hollway, W. and Haavind, H. (2013) Culture as a process lived through the person: Becoming a Bangladeshi mother in London. Qualitative Inquiry 19(6): 470-479.

Walkerdine, V. ( 2010) Communal beingness and affect: An exploration of trauma in an exindustrial community. Body \& Society, 16(1): 91-116.

Walkerdine, V. (2014) Felix Guattari and the Psychosocial Imagination, Journal of Psychosocial Studies 8(1): 146-158

Wetherell, M. (2008) Subjectivity or Psycho-Discursive Practices? Investigating Complex Intersectional Identities. Subjectivity 22(1), 73-81.

Woodward, K. (2015) Psychosocial Studies: An Introduction. London: Routledge. 